\title{
New Algorithm for Microstructural Information Determination from the Overlapping X-ray Diffraction Profiles
}

\author{
Krešimir Dekanić, ${ }^{1}$ Željko Skoko $^{1} *$ and Sven Lončarić ${ }^{2}$ \\ ${ }^{1}$ Department of Physics, Faculty of Science, University of Zagreb, Bijenička c. 32, 10000 Zagreb, Croatia \\ ${ }^{2}$ Department of Electronic Systems and Information Processing, Faculty of Electrical Engineering and Computing, \\ University of Zagreb \\ * Corresponding author: E-mail: zskoko@phy.hr \\ Tel. no.: +38514605555, fax: +38514680336
}

Received: 23-08-2016

\begin{abstract}
Knowledge about the microstructure is crucial in targeted synthesis of novel nanomaterials. The microstructural parameters, crystallite size and crystallite strain play a major role in physical and chemical properties of the material. X-ray diffraction (XRD) is a very suitable method for this task, since it is non-destructive and it enables a very quick and precise determination of these parameters. The main problem lies in the case where the two neighboring diffraction profiles overlap each other. Here we present a new method for the separation of the overlapping profiles based on the differentiation of the profiles. Further, this method is appropriate for non-crystallographers working in the field of material science since it does not require any crystallographic experience and the full knowledge about the structure of the sample investigated. The microstructural results obtained by the proposed method are very accurate.
\end{abstract}

Keywords: Separation of the overlapping diffraction profiles, differentiation, Fourier transformation, X-ray diffraction, microstructure, nanomaterials

\section{Introduction}

$\mathrm{X}$-ray diffraction $(\mathrm{XRD})$ is a major non-destructive technique used for structure determination of materials. Diffraction pattern represents the sample's response to the excitation by the x-rays, and various information about the crystal structure can be obtained from it (phase identification, quantitative phase analysis, information about crystallite size and defects, etc.). ${ }^{1,2}$ Even though this method is routinely used in the laboratories throughout the world, the interpretation of the diffraction pattern is not straight-forward. There are several problems, which should be dealt with before tackling the problem of structure determination. One of the major obstacles is the overlap of the neighboring maxima, and here we present a method for tackling this predicament.

The first step is to identify the contribution of the instrument to the pattern and remove it. In the ideal case, with the ideal instrument and the ideal sample (indefini- tely large crystals and perfect crystal lattice with no defects) the observed diffraction profile would be the $\delta$-function located at the Bragg angle - as determined by the crystallographic plane spacing. In reality, there are many contributions to the diffraction peak finite width. Profile broadening can be separated into two groups - instrumental broadening and the sample broadening. It arises from the instrumental imperfections (slit widths, sample size, penetration in the sample, imperfect focusing, unresolved $\alpha_{1}$ and $\alpha_{2}$ peaks, wavelength widths of $\alpha_{1}$ and $\alpha_{2}$ in cases where the peaks are resolved, etc.). To correct for instrumental broadening, usually a diffraction pattern of a standard is taken. Standard is the sample in which the particle size is large enough to eliminate the broadening due to the small crystallite size and which is deformationfree. The diffraction pattern of standard is taken under the same condition as the sample, so that the broadening of standard is equal to the instrumental broadening. On the other hand, the sample broadening arises from the crystal 


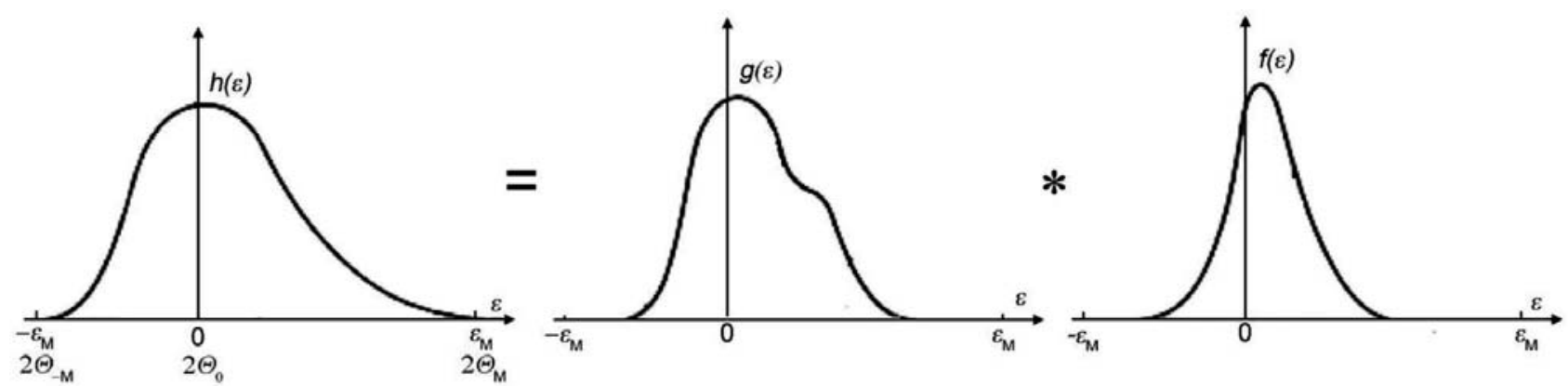

Figure 1. Observed, pure diffraction and instrumental profile.

sample imperfections solely. And this broadening is to be analyzed in order to obtain information about the sample microstructure, namely, small crystallite size, strains and faultings. There are several methods about how one could correct for the instrumental broadening, but the most precise one is by Fourier series method - the so-called Stokes method. $^{3}$

Observed diffraction profile, $h(\varepsilon)$, is a convolution of two profiles: the instrumental profile, $g(\varepsilon)$, and the pure diffraction profile, $f(\varepsilon)$ (Figure 1).

The convolution equation can be written in the following way:

$$
h(\varepsilon)=\int_{-\infty}^{+\infty} g(t) f(\varepsilon-t) \mathrm{d} t .
$$

The variable $\varepsilon$ measures the angular deviation of a point from the true Bragg angle $2 \Theta_{0} ; \varepsilon$ and the auxiliary variable $t$ has the dimension of $2 \Theta . h(\varepsilon)$ and $g(\varepsilon)$ can be experimentally measured, whereas the $f(\varepsilon)$ is the function that we are trying to determine.

Profiles can be written in the following way:

$$
\begin{aligned}
& h(\varepsilon)=\sum_{t=-\varepsilon_{M}}^{+\varepsilon_{M_{M}}} H(t) \exp \left(-\mathrm{i} \pi \frac{\varepsilon \cdot t}{\varepsilon_{M}}\right), \\
& g(\varepsilon)=\sum_{t=-\varepsilon_{S^{M}}}^{+\varepsilon_{S_{M}}} G(t) \exp \left(-\mathrm{i} \pi \frac{\varepsilon \cdot t}{\varepsilon_{M}}\right), \\
& f(\varepsilon)=\sum_{t=-\varepsilon_{M}}^{+\varepsilon_{M}} F(t) \exp \left(-\mathrm{i} \pi \frac{\varepsilon \cdot t}{\varepsilon_{M}}\right) .
\end{aligned}
$$

The Fourier coefficients of the two experimentally measured profiles can be written by the following summations:

$$
\begin{aligned}
& H_{r}(t)=h(0)+\sum_{t=1}^{+\varepsilon_{V}}[h(\varepsilon)+h(-\varepsilon)] \cos \left(\pi \frac{\varepsilon \cdot t}{\varepsilon_{M}}\right) \\
& H_{i}(t)=\sum_{\varepsilon=1}^{+\varepsilon_{V}}[h(\varepsilon)-h(-\varepsilon)] \sin \left(\pi \frac{\varepsilon \cdot t}{\varepsilon_{M}}\right),
\end{aligned}
$$

$$
\begin{aligned}
& G_{r}(t)=g(0)+\sum_{t=1}^{+\varepsilon_{M}}[g(\varepsilon)+g(-\varepsilon)] \cos \left(\pi \frac{\varepsilon \cdot t}{\varepsilon_{M}}\right), \\
& G_{i}(t)=\sum_{\varepsilon=1}^{+\varepsilon_{M}}[g(\varepsilon)-g(-\varepsilon)] \sin \left(\pi \frac{\varepsilon \cdot t}{\varepsilon_{M}}\right) .
\end{aligned}
$$

Fourier integral theorem allows the calculation of the real and imaginary coefficients $F(t)$ of the sought pure diffraction profile $f(t)$ in the following way:

$$
\begin{gathered}
F_{r}(t)=\frac{H_{r}(t) G_{r}(t)+H_{i}(t) G_{i}(t)}{G_{r}^{2}(t)+G_{i}^{2}(t)}, \\
F_{i}(t)=\frac{H_{i}(t) G_{r}(t)-H_{r}(t) G_{i}(t)}{G_{r}^{2}(t)+G_{i}^{2}(t)} .
\end{gathered}
$$

There coefficients can now be used in two ways, in two different models, in order to obtain microstructural information about the sample.

First model, the so-called Warren-Averbach-Bertaut model directly uses the obtained Fourier coefficients to interpret the pure diffraction profile. ${ }^{4}$

In this model, the order of the Fourier coefficients is transformed into order $L$ by the following relation:

$$
L=\frac{\lambda \cdot t}{4\left(\sin \Theta_{M}-\sin \Theta_{0}\right)} .
$$

Here, $\lambda$ is the wavelength of $x$-ray radiation used in the experiment, $\Theta_{0}$ is the position of the center of the profile, and $\Theta_{M}$ is the limit of the profile (angular). From this, the average area-weighted crystallite size can readily be obtained by the following formula:

$$
\langle L\rangle_{A}=-\frac{1}{\frac{\mathrm{d} F(L)}{\mathrm{d} L}}
$$

In other words, a relationship $F(L)$ vs. $L$ should be plotted, then the tangent from the first point (zeroth) Fourier coefficient) should be calculated, and the intercept with the $\mathrm{x}$-axis gives the crystallite size. 
The other model, Scherrer method, does not directly use the obtained Fourier coefficients, but it requires the synthesis of the diffraction profile.

Working formula for this synthesis is:

$$
\begin{aligned}
f(\varepsilon)= & F_{r}(0)+2 \sum_{t=1}^{t^{\prime}}\left[F_{r}(t) \cos \left(\pi \frac{\varepsilon \cdot t}{\varepsilon_{M}}\right)+\right. \\
& \left.+F_{i}(t) \sin \left(\pi \frac{\varepsilon \cdot t}{\varepsilon_{M}}\right)\right],
\end{aligned}
$$

Once the diffraction profile has been obtained by the above formula, its integral breadth can then be used to obtain different microstructural information. For more details, see for example Skoko et al. ${ }^{3}$

One of the most common used approaches is the use of Scherrer formula, because of its simplicity but sufficient accuracy. Crystallite size - as defined by Scherrer is the average volume-weighted crystallite size and it is given by the following relation:

$$
\langle L\rangle_{V}=\frac{K \lambda}{\beta \cos \Theta}
$$

where $K$ is the dimensionless shape factor with a value close to unity, usually taken to be $0.94 ; \lambda$ is the wavelength of the radiation used in the experiment; $\beta$ is the integral breadth of the profile. ${ }^{5}$

The major drawback of the Stokes method is that it does not allow for the overlap of the neighboring profiles, which is very common in real-life measurements. In this case, some approximations must be taken into account in order to separate the two (or more) profiles.

Usually, the diffraction profile, after the correction for instrumental broadening, can be expressed by the following functions: $:$,7

Gauss function, $G(\Theta)=a \cdot \exp \left(-\frac{(\Theta-b)^{2}}{2 c^{2}}\right)+d$, where $a, b$ and $c$ are arbitrary constants,

Lorentz function, $L(\Theta)=\frac{1}{\pi} \frac{\frac{1}{2} \Gamma}{\left(\Theta-\Theta_{0}\right)^{2}+\left(\frac{1}{2} \Gamma\right)^{2}}$, where $\Gamma$ is the parameter specifying the width, and maximum is located at $\Theta_{0}$, which in the X-ray diffraction theory is called the Bragg angle

Voigt function, which is a convolution of Gauss and Lorentz function, $V(\Theta)=\int_{-\infty}^{\infty} G\left(\Theta^{\prime}\right) L\left(\Theta-\Theta^{\prime}\right) \mathrm{d} \Theta^{\prime}$, seudoVoigt which a linear combination of Gauss and Lorentz function, $P V(\Theta)=(1-\eta) G(\Theta)+\eta L(\Theta)$, where $\eta$ is a constant determining weight of Gauss and Lorentz functions.

\section{Materials and Methods}

Here, we present a method for separation of the neighboring overlapping profiles based on the differentiation - one of the methods for resolution enhancement.
Even though this method has been used in the problems of spectroscopy for some time,$^{8,9,10}$ the full potential of the method was never truly exploited and as far as the authors know this method was never used in the analysis of the XRD profiles. Basic principles behind this method are quite clear - differentiation amplifies higher frequency components of the profile more than lower frequency components. This idea was firstly proposed by Tikhonov, ${ }^{11}$ and almost at the same time by Allen, Gladney and Glarum, ${ }^{12}$ using as the basis the fact that in the Fourier space differentiation corresponds to multiplication with independent variable. Allen et al. ${ }^{12}$ stated that if the maximum is symmetric and has a smooth Fourier transform one can subtract the second (and higher) derivatives from the original maximum in order to enhance its intensity. Flow chart of the algorithm is given on the Figure 2. We have tried several approaches, regarding the order of the derivative, and by far the best results were obtained when using the subtraction of the second order derivative from the original profile.

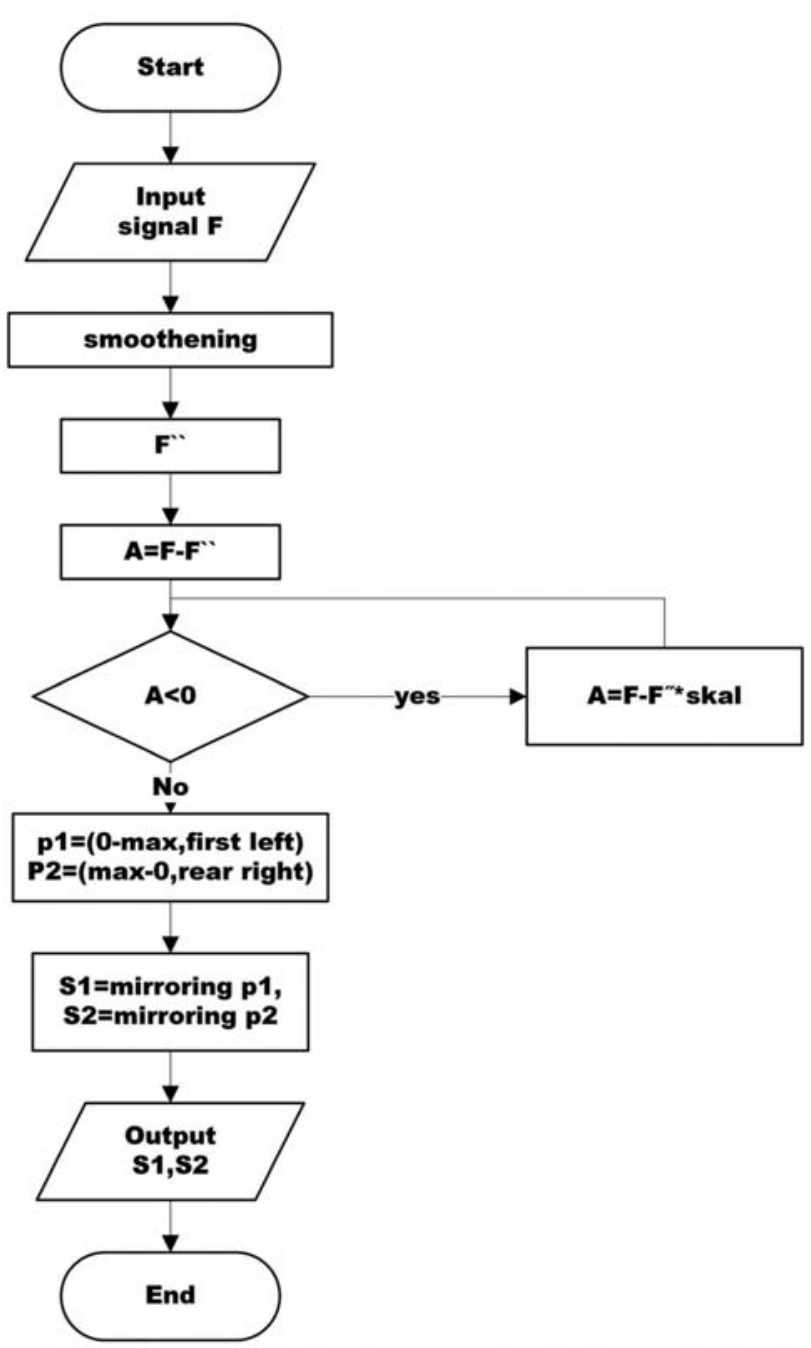

Figure 2. Flow chart of the algorithm 
The method was tested for the synthesized Gauss profiles. It was applied for different amounts of overlap, from two fully separate profiles (overlap 0\%) to profiles that were overlapped so much as to hardly differentiate the positions of two maxima (overlap 30\%). It was also tested for Lorentz function but results were better for Gauss profiles.

In order to test the validity of the method, resolved profiles obtained in this way were compared to the two original profiles which were used to get the overlapped profiles. After that, presumed crystallite sizes were calculated by the two afore mentioned methods: Warren-Averbach and Scherrer methods and compared to the values obtained from the original profiles.

Here are given the graphical results for the estimated amount of the overlap of $10 \%$.

Two overlapped profiles are shown on Figure 3.

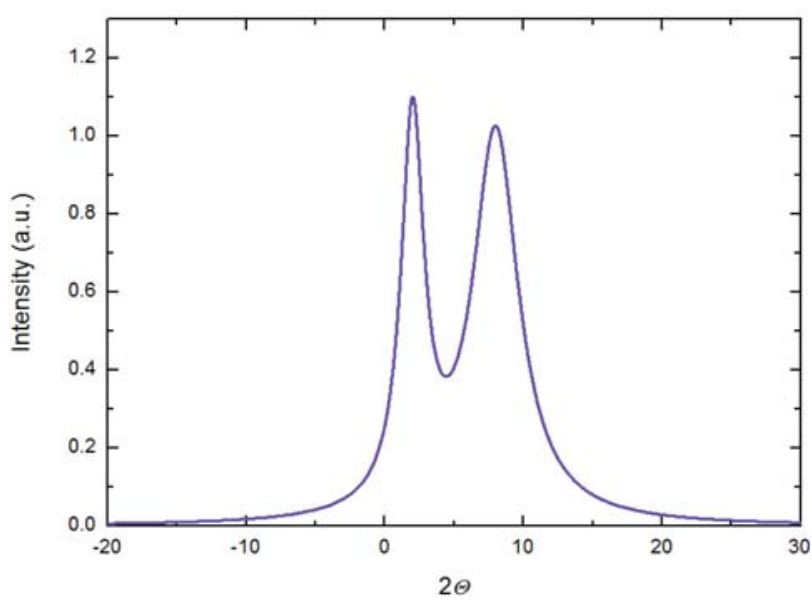

Figure 3. Two overlapped profiles, defined by Gauss functions.

Individual profiles, as well as their summation, are shown on Figure 4. From it can clearly be seen that the summarized profile differs from the individual ones. Total profile is broader, and the saddle between two maxima is quite high. For the sake of reality, the profiles were chosen so that their intensities, as well as widths, are mutually different.

Next step is the calculation of the second derivative. Calculation is done by the program OriginPro8. At this point one should be very careful, because the simple summation of the original profile with its second derivative will result with negative values at some points. For that purpose, second derivative should be scaled by the arbitrary factor, in order that the resulting profile is positive in its whole domain. The scaling factor should be chosen in such a way that the negative sides of the inverted second derivative are a mirror image of the sides of the original peak over the regions where the summation would be negative. In our measurements, it shows that the best results were obtained for the values of the scaling factor 0.2-0.4. Original profiles and the scaled second derivative are shown on Figure 5.

Final result is shown on Figure 6. It is clearly seen from the Figure 6 . that the intensities of both maxima are increased and the saddle is decreased.

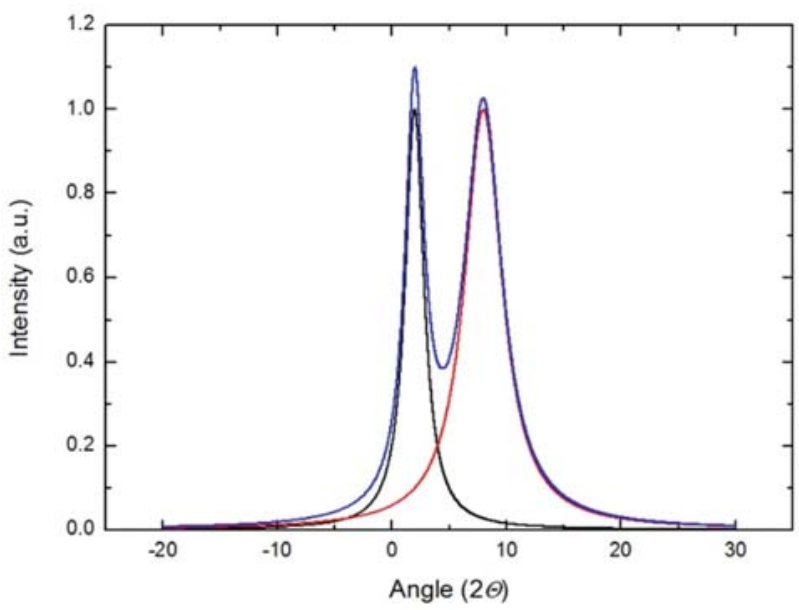

Figure 4. Two individual profiles defined by Gauss functions, with different intensities and widths. Their summation is shown by the blue line.

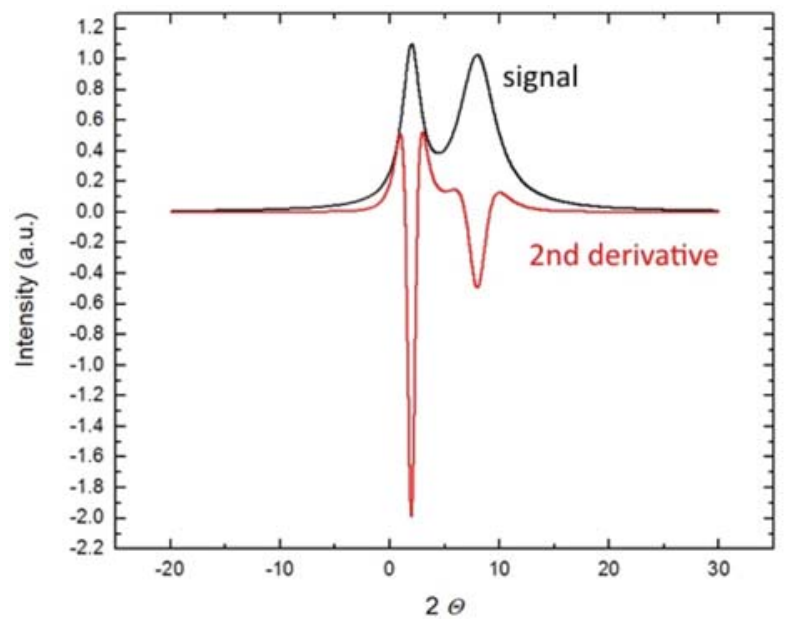

Figure 5. Synthesized profile, consisting of two overlapped profiles, labeled in black. $2^{\text {nd }}$ derivative of the profile, labeled in red. $2^{\text {nd }}$ derivative is scaled so as to give the positive values in the whole range, when subtracted from the profile.

In order to fully separate the profiles, which are once enhanced by the method explained earlier, following steps were performed:

small-angle side, up to the maximum value, of the left-hand profile was chosen and it was mirrored to the high angle side. In this way, the left-hand profile was isolated. Full symmetrical profile was obtained, which is in accordance with the started profile described by the Gauss 


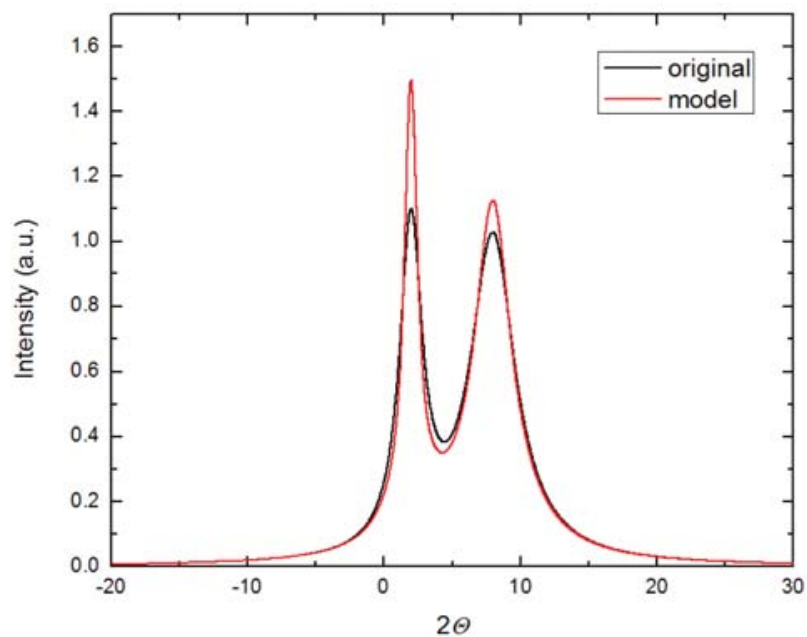

Figure 6. Original profile labeled in black, and enhanced profile (obtained by the summation of the original profile and the negative scaled $2^{\text {nd }}$ derivative) labeled in red.

function and also with the real-life experiments where diffraction maxima are usually symmetrical.

The same procedure was then repeated for the highangle side of the right-hand profile.

Comparison of the resolved and original profiles is shown on the Figure 7. For the sake of easier visual comparison, profiles were scaled to the same intensity.

From visual inspection it is obvious that better results are obtained for the broader profile, as shown on the left of the Figure 6. In this case, the resolved and original profiles are almost identical. For the narrower profile, the two profiles do not coincide totally, but the difference is almost negligible.

\section{Results and Discussion}

\section{1. Analysis and the Results of the Simulation Study}

Finally, the crystallite sizes were calculated from the separated and original profiles, as already mentioned. The results are given in the table 1.

As can be seen from the Table 1., obtained results are quite satisfactory. Crystallite sizes for the first (lefthand) profile are 72(2) nm for the original profile, compa-
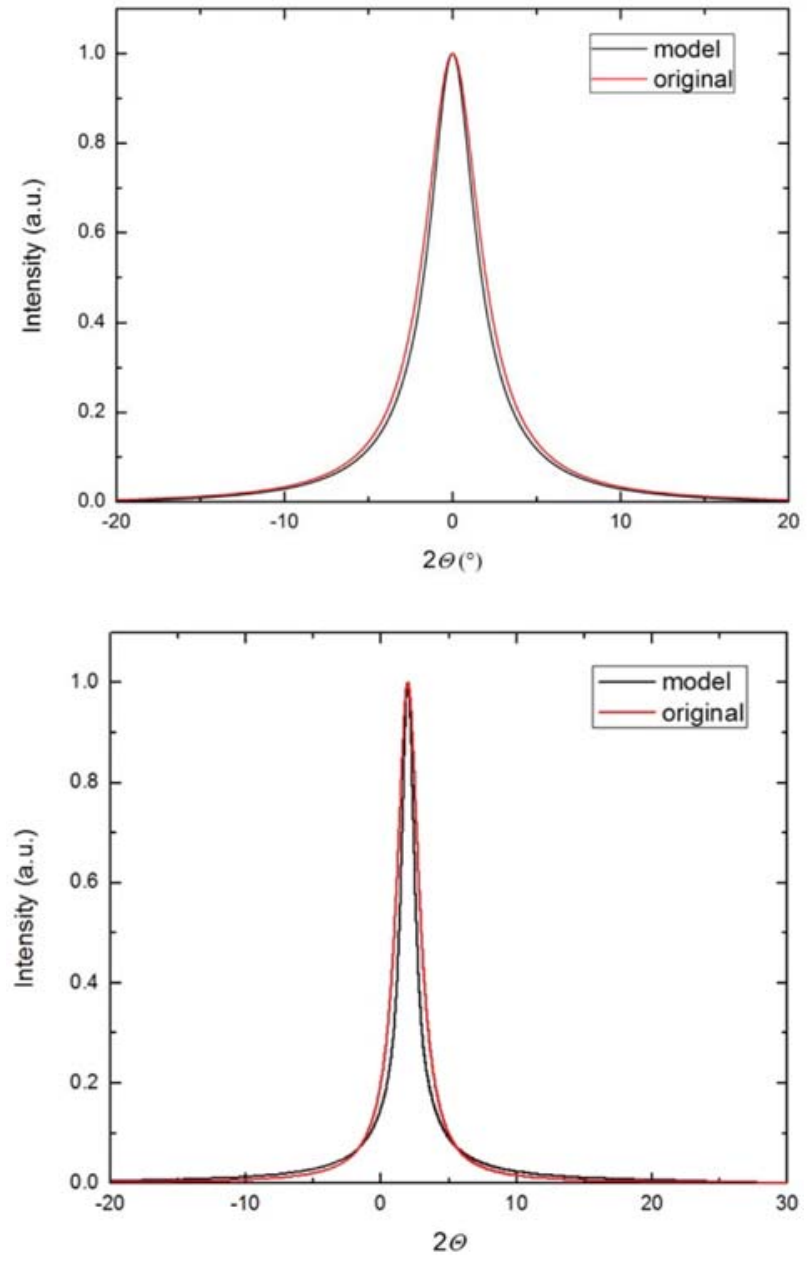

Figure 7. Comparison of the separated profiles with the original ones.

red to the 75(4) nm for the resolved sample, obtained by the Warren-Averbach (WA) method. That is a difference of $4 \%$. Corresponding values for the same profile, obtained by the Scherrer method are 80(6) $\mathrm{nm}$ and 83(3) nm, respectively, differing from each other by $4 \%$. For the second (right-hand) profile the values of the crystallite size amount to 16(1) nm for the original profile and 17(2) nm for the resolved profile, as calculated by the WA method, difference being 6\%. For the Scherrer method, obtained values amounted to 20(4) $\mathrm{nm}$ for the original profile and 21(8) for the resolved, difference being $4 \%$. It is obvious that the obtained results are higher for the resolved profi-

Table 1. Result of the microstructural analysis. Crystallite sizes as obtained from the Warren-Averbach (WA) method and Scherrer method, for the original and resolved profiles

\begin{tabular}{lcccccc}
\hline Profile & $\begin{array}{c}\text { Size - WA } \\
\text { (original } \\
\text { profile, nm) }\end{array}$ & $\begin{array}{c}\text { Size - WA } \\
\text { (resolved } \\
\text { profile, nm) }\end{array}$ & Error (\%) & $\begin{array}{c}\text { Size-Scherrer } \\
\text { (original } \\
\text { profile, } \mathbf{n m})\end{array}$ & $\begin{array}{c}\text { Size - Scherrer } \\
\text { (resolved } \\
\text { profile, nm) }\end{array}$ & Error (\%) \\
\hline (left) & $72(2)$ & $75(4)$ & $4 \%$ & $80(6)$ & $83(3)$ & $4 \%$ \\
(right) & $16(1)$ & $17(2)$ & $6 \%$ & $20(4)$ & $21(8)$ & $5 \%$ \\
\hline
\end{tabular}


les than for the original profiles. The reason for that is that in the course of the separation of the two profiles, errors are necessarily made and the width of the obtained profile is smaller than the original one. Since crystallite size is inversely proportional to the width of the profile, obtained values are always bigger. One might argue that the obtained errors - between 4 and $6 \%$ - are large, but things should be put in a broader perspective. Nanomaterials are defined as materials that have crystallite size between $1-100 \mathrm{~nm}$, and they possess unique optical, electronic and mechanical properties. On that scale, error margin of $6 \%$ is totally acceptable.

\section{2. Analysis and the Results of the Experimental Study}

The method was also tested on real-life examples. For this purpose, the actual material of LaB6 (which is used as a NIST (National Institute of Standard \& Technology) standard) was recorded on the Philips diffractometer, model PW1820 in Bragg-Brentano geometry, in the $2 \Theta$ range $10-100^{\circ}$, with the step size of $0.01^{\circ}$ and measuring time od $1 \mathrm{~s} / \mathrm{step}$. The two overlapping diffraction peaks at around $66.5^{\circ}$ are shown on the Figure 8.

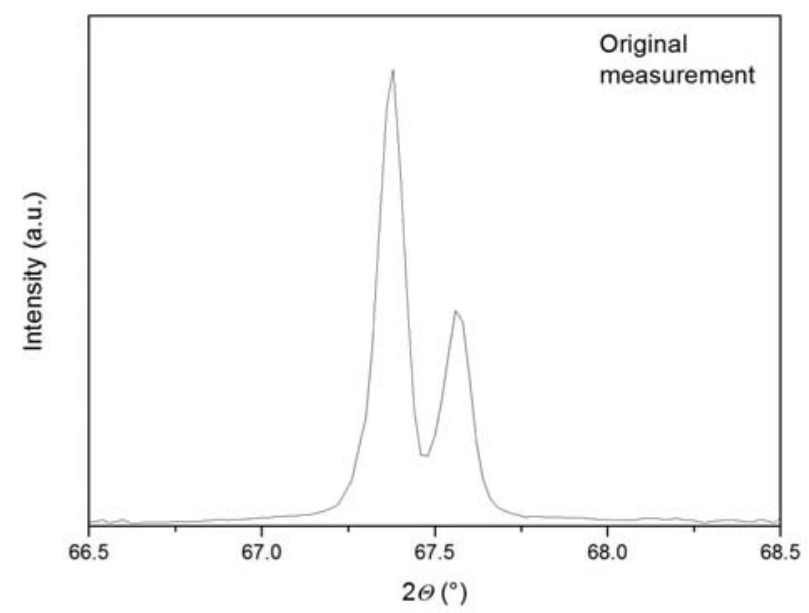

Figure 8. X-ray diffraction of the $\mathrm{LaB}_{6}$ sample (around $67.5^{\circ}$ ).

Original sample and its second derivative is shown on the Figure 9.

Results of the proposed algorithms for the left-hand profile and right hand profile are profile in the Figure 10 and 11.

In order to check the validity of the microstructural parameters obtained by this method, the parameters were also calculated by the Rietveld method that requires the full knowledge of the crystal structure of the sample and is time demanding. Details about the method can be found elsewhere. ${ }^{13}$ All the calculations were performed by the software X'Pert HighScore Plus, v. 3.0, by PANalytical B.V.

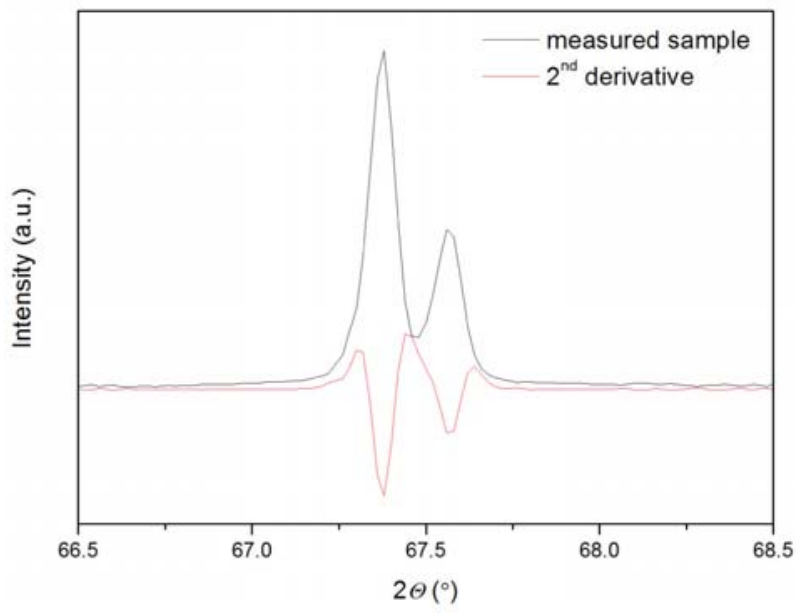

Figure 9. The original $\mathrm{LaB}_{6}$ profile and its $2^{\text {nd }}$ derivative.

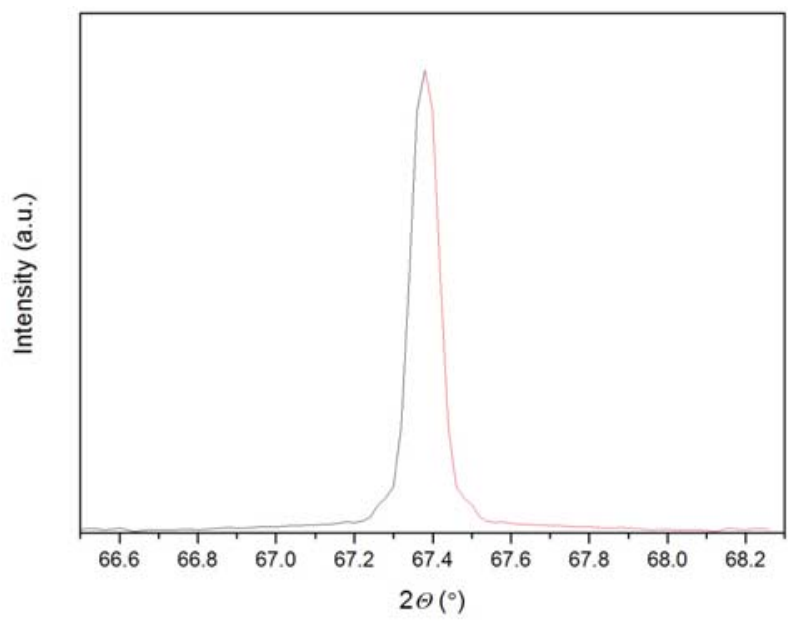

Figure 10. The result of the analysis for the left-hand profile.

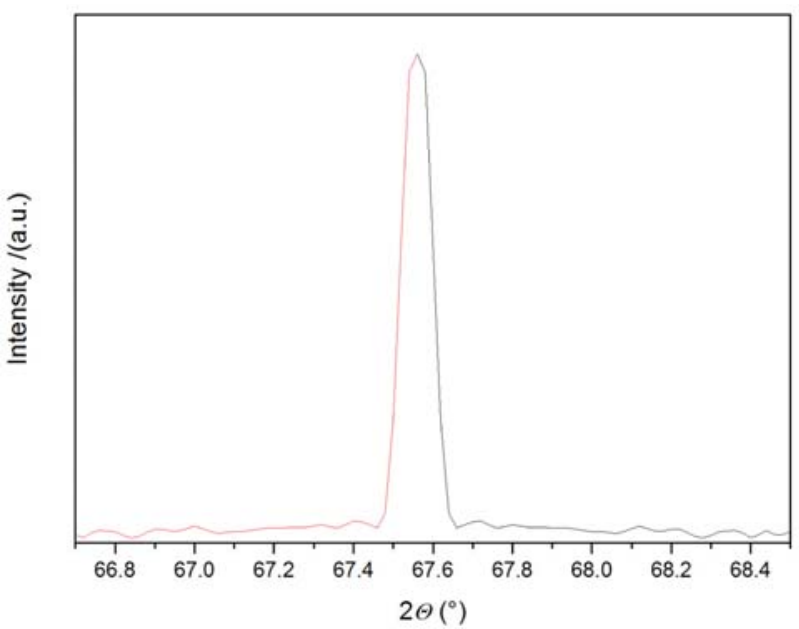

Figure 11. The result of the analysis for the right-hand profile.

Crystallite sizes were calculated by the routine implemented in the software for the pseudo-voigt profile function. 
Table 2. Calculated crystallite sizes obtained by this method and comparison to those obtained by Rietveld analysis for the real samples.

\begin{tabular}{lccc}
\hline Profile & $\begin{array}{c}\text { Size }- \text { Rietveld analysis } \\
\text { (original profile, } \mathbf{n m})\end{array}$ & $\begin{array}{c}\text { Size - proposed method } \\
\text { (resolved profile, } \mathbf{n m})\end{array}$ & Error (\%) \\
\hline (left) & $153(6)$ & $156(4)$ & $2 \%$ \\
(right) & $162(7)$ & $166(4)$ & $2 \%$ \\
\hline
\end{tabular}

Calculated crystallite sizes obtained by this method, and comparison to results obtained by Rietveld method are shown in the Table 2.It is obvious that the results obtained from this method are in excellent agreement with the results obtained by the Rietveld method.

\section{Conclusion}

In this article we have presented a method for separation of overlapped X-ray diffraction profiles. Even though the method is already known and has been tested on several problems in spectroscopy, to the best of our knowledge, the method has never been applied in the field of X-ray diffraction. There are other, mainly commercial, solutions to this problem - mostly by the way of Rietveld refinement, but they all require formal knowledge of crystallography. Main advantage of the proposed method lies in the fact that it can be applied by non-crystallographers working in the field of material science. The method has been tested on the original profiles (before they were overlapped) and the results are quite satisfactory.

\section{References}

1. B. E. Warren, Prog. in Met. Phys. 1959, 8, 147-202. http://dx.doi.org/10.1016/0502-8205(59)90015-2

2. B. E. Warren, X-ray Diffraction; Addison-Wesley, New York,
1969.

3. Z. Skoko, J. Popovic., K. Dekanic, V. Kolbas, and S. Popovic, J. Appl. Crystallogr. 2012, 45, 594-597. http://dx.doi.org/10.1107/S0021889812014859

4. B. E. Warren and B. L. Averbach, J Appl. Phys. 1950, 21, 595-599. http://dx.doi.org/10.1063/1.1699713

5. P. Scherrer, Nachr. Ges. Wiss. Gött., Math.-Phys. Kl. 1918, 2 , 98-100.

6. D. Balzar and H. Ledbetter, J. Appl. Crystallogr. 1993, 26, 97-103. http://dx.doi.org/10.1107/S0021889892008987

7. D. Balzar, N. Audebrand, M. Daymond, A. Fitch, A. Hewat, J. I. Langford, A. Le Bail, D. Louër, O. Masson, C. N. McCowan, N. C. Popa, P. W. Stephens, and B. H. Toby, J. Appl. Crystallogr. 2004, 37, 911-924. http://dx.doi.org/10.1107/S0021889804022551

8. M. Hegland and R. S. Anderssen, R. S Inverse Problems 2005, 21, 915-934. http://dx.doi.org/10.1088/0266-5611/21/3/008

9. R. S. Anderssen and M. Hegland, J. Integral Equ. Appl. 2010, 22, 355-367. http://dx.doi.org/10.1216/JIE-2010-22-3-355

10. P. R. Wiley, G. J. Tanner, P. M. Chandler, and R. S. Anderssen, J. Agric. Food Chem. 2009, 57, 4042-4050. http://dx.doi.org/10.1021/jf9001523

11. A. N. Tikhonov, Sov. Math. Dokl. 1963, 4, 1035-1038.

12. L. C. Allen, H. M. Gladney, and S. H. Glarum, J. Chem. Phys. 1964, 40, 3135-3141. http://dx.doi.org/10.1063/1.1724976

13. H. Rietveld, J. Appl. Cryst. 1969, 2, 65-71. http://dx.doi.org/10.1107/S0021889869006558

\section{Povzetek}

Pri sintezi novih nanomaterialov je poznavanje mikrostrukture ključnega pomena. Pomembno vlogo pri fizikalnih in kemijskih lastnostih materiala imajo mikrostrukturni parametri, kot so velikost kristalitov in napetosti v kristalitih. Rentgenska praškovna difrakcija (XRD) je zelo primerna metoda za to nalogo, saj je nedestruktivna in omogoča zelo hitro in natančno določanje teh parametrov. Težave pri interpretaciji rezultatov nastanejo v primerih, ko pride do prekrivanja dveh sosednjih difrakcijskih vrhov. V prispevku smo predstavili novo metodo za ločevanje prekrivajočih difrakcijskih vrhov, ki temelji na diferenciaciji profilov. Metoda je primerna tudi za raziskovalce, ki delajo na področju raziskav materialov in niso strokovnjaki za kristalografijo, saj ne zahteva obilo izkušenj s področja kristalografije in znanja o strukturi preiskovanega vzorca. Rezultati mikrostrukturnih parametrov pridobljenih s predlagano metodo so zelo natančni. 